\title{
Pathophysiology and Biomechanics of the Aging Spine
}

\author{
Michael Papadakis ${ }^{*}, 1$, Georgios Sapkas ${ }^{2}$, Elias C. Papadopoulos ${ }^{1}$ and Pavlos Katonis ${ }^{3}$ \\ ${ }^{1} 2^{\text {nd }}$ Orthopaedic Clinic, University of Athens, Greece \\ ${ }^{2} 1^{\text {st }}$ Orthopaedic Clinic, University of Athens, Greece \\ ${ }^{3}$ Orthopaedic Clinic, University of Crete, Greece
}

\begin{abstract}
Aging of the spine is characterized by two parallel but independent processes: the reduction of bone mineral density and the development of degenerative changes. The combination of degeneration and bone mass reduction contribute, to a different degree, to the development of a variety of lesions. This results in a number of painful and often debilitating disorders. The present review constitutes a synopsis of the pathophysiological processes that take place in the aging spine as well as of the consequences these changes have on the biomechanics of the spine. The authors hope to present a thorough yet brief overview of the process of aging of the human spine.
\end{abstract}

Keywords: Spine, biomechanics, osteoporosis, osteoarthritis.

The human spine is a modular structure, whose role is to protect neural elements, to support the trunk in the upright position and allow motion [1]. From the axis to the sacrum, it is composed of alternating subunits, the bony vertebrae and the fibrocartilagenous intervertebral disks. The decrepitude of the spine causes changes in the structure as well as the shape of its parts, which result in encroachment and irritation of the very same neural elements it should protect, degradation of trunk supporting capability and limitation of motion, all of which manifest as painful syndromes.

Aging of the spine is characterized by two parallel but independent processes: reduction of bone mass and development of degenerative changes. These processes run contemporaneously, but at different rates. The gravity of each one is different from person to person. In addition, on an individual level, the degree of affliction is dissimilar for the various spinal levels.

The combination of degeneration and bone mass reduction contribute, to a different degree, to the development of a variety of lesions. The course these processes take as well as their biomechanical consequences are analyzed separately for each component of the spine.

\section{INTERVERTEBRAL DISK}

The intervertebral disk is composed of the gelatinous nucleus pulposus, which is surrounded by the annulus fibrosus. The nucleus contains small numbers of undifferentiated and differentiated chondrocytes and connective tissue cells. Its ground substance constitutes mostly of water, up to $88 \%$, and a mixture of glycoproteins. There are no blood vessels or nerve endings in the nucleus. Nutrient exchange is achieved through minute pores in the end plate cartilage on either side. The hydroabsorptive properties of

*Address correspondence to this author at the $2^{\text {nd }}$ Orthopaedic Clinic, University of Athens, Greece; Tel: 0036942489890 ;

E-mail:michalpap@gmail.com the nucleus' proteins cause fluid to osmotically seep through these pores. Thus, being enclosed in a rigid case, the nucleus pulposus develops hydrostatic pressure, which contributes in resisting forces that are applied centrically (axial compression) or eccentrically (flexion-extension, lateral bending) (Fig. 1).

The annulus fibrosus consists of successive layers of collagen fibers. The direction of these fibers is oblique, and each layer has the opposite direction from its adjacent ones. This configuration imparts added resistance to rotation forces. Additionally, resistance to shear forces is exerted exclusively by the annulus [2], while removing the nucleus has no effect on the disk's behaviour to these forces [3].

Disk kinematics are divided in two phases. Beginning in the neutral position, the annulus fibres are slack. The application of a load will initially cause a small deformation of the disk, up to the point where the fibres become taut. Very little resistance is exerted in that initial part of motion, as there is no elastic distension. This is the neutral zone of the disk's range of motion, where an applied load can easily deform disk shape without significant resistance. Should the load be great enough, it will cause a greater deformation. The fibres will then stretch and the nucleus will be forced to change shape. This is the elastic zone, where the stiffness of the disk increases proportionally to the deformation caused by the applied load $[1,4]$.

The above mentioned facts underline that the nucleus and annulus constitute a functional unit, whose effectiveness depends on the integrity of each constituent. If the disk's internal pressure were diminished or the integrity and structure of the annulus were disrupted, the mechanical properties of the entire disk would degrade [5].

Disk degeneration begins when the balance between synthesis and degradation of the matrix is disrupted. At a microscopic level, findings of disc degeneration include a net loss of water and glycoproteins, disruption of collagen fiber organization and increased levels of proteolytic 

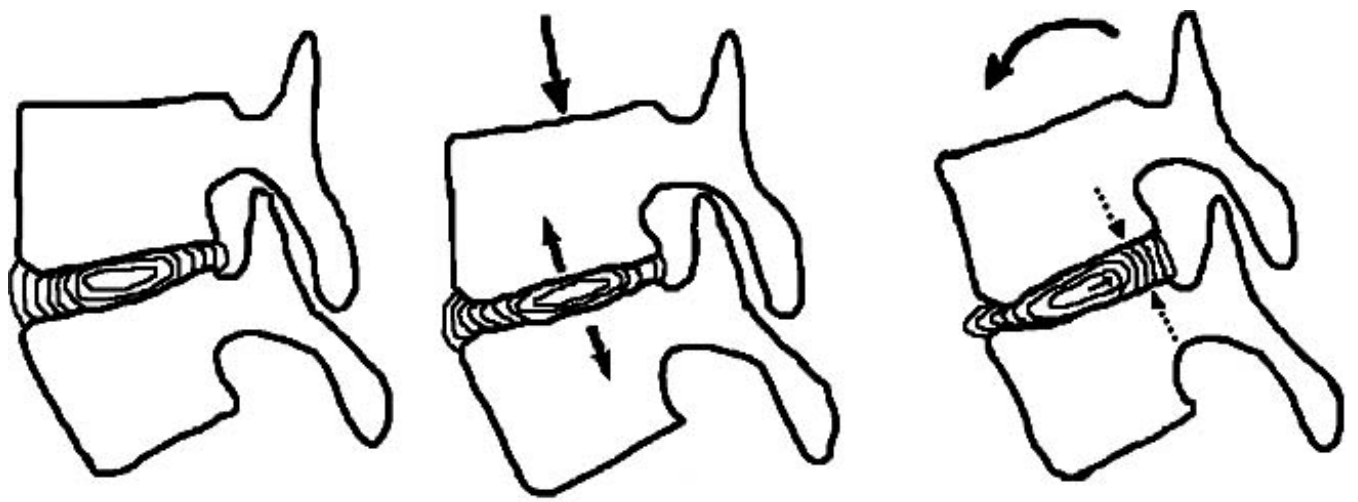

Fig. (1). Self-regulation of the disk. Even in the steady state, the nucleus tends to expand but is restrained by the end-plates and the annulus. During axial compression, nucleus' hydrostatic pressure rises, which counteracts the deformation. During flexion (in extension and lateral bending respectively) annulus fibers are stretched and the nucleus is pushed to the opposite side. The nucleus forces the fibers to return to their original state, thus countering the motion.

enzymes. This alteration of disk cell's metabolism is induced by aging and, to a large degree, depends on genetic predisposition [6]. Additionally, it has been observed that continuous or repetitive loading above or even below normal levels is related to an increase in proteolytic enzymes [7]. The concurrent degeneration of the epiphyseal plates, described in more detail later on, reduces their permeability and the consequent diminution of nutrients also has a detrimental effect [8]. Degeneration is associated with penetration of nerves and vessels in the normally avascular nucleus $[9,10]$. Vascular cells produce an array of cytokines and proteases, thus stimulating further degeneration as well as inflammation. The inflammatory cells that accompany the angiogenesis in turn produce more cytokines and proteases, thus creating a vicious circle that self-amplifies. The nerve fibres that infiltrate together with the vessels carry painful stimuli, making the disk a source of pain.

These cellular and biochemical modifications bring about macroscopic anatomical alterations $[6,11]$. The loss of water content causes a reduction in disk height [12]. The nucleus' ground substance is replaced by collagen fibers and the boundary between the nucleus and the annulus becomes blurred. At the final stages of this process, the disk appears homogeneous and collapsed (black disk on MRI). The dehydrated annulus becomes more brittle, and concentric cracks and linear crevices begin to appear. Some of the changes observed on the end-plate include an increase in vascularity, thinning and formation of cracks of the cartilage, as well as sclerosis of the subchondral bone. The disk becomes gradually dislodged from the vertebral rim, and osteophytes replace Sharpey's fibres. These degenerative changes reduce the mechanical strength of the annulus fibrosus and end-plates, both in total and locally by the formation of weak points. The result is that the disk can either bulge as a whole or protrude through said weak points. This occurs on the horizontal plane, causing either bulging or herniations, as well as on the vertical plane, causing either end plate concavity or Schmorl's nodes.

The modification of the kinematic properties of the intervertebral disk that come about with degeneration have been thoroughly studied. Loss of height entails that the annulus fibres are more relaxed [4]. As a result a greater displacement is needed before they are stretched, and begin to resist deformation. In the early stages of degeneration therefore the neutral zone increases in all directions, like the results of experimental measurements have shown [13]. As degeneration progresses, the modulus of elasticity of the intervertebral disk increases [14], i.e. it becomes more hard and stiff, and so the range of motion begins to decline. Hence, while in the early stages of degeneration the neutral zone and accordingly instability increase, in advanced stages motion is reduced $[13,15,16]$ until disk collapse and osteophyte formation result in spontaneous fusion [17].

The manner in which loads are transferred through the disk is also of particular importance. Normally, when a force is applied either centrally (axial load) or eccentrically (flexion-extension, lateral bending), it is evenly distributed on the entire disk, because of its hydrostatic properties [18]. The healthy nucleus pulposus behaves like a liquid but as degeneration progresses, it acquires the behaviour of a solid $[18,19]$. Consequently, a degenerate disk no longer behaves hydrostatically [20]. Due to its low water content, application of loads causes a greater loss of height than normal, and the disk tends to bulge [12]. Since the degenerate disk can not withstand compressive loads, the surrounding structures are called to bear at least part of them. This phenomenon is called stress shielding, and it constitutes a physiological process in order to protect injured tissues [21]. Hence, while in the healthy spine only $5-10 \%$ of load is transmitted through the posterior arch, the presence of degenerate disks raises this fraction to $40 \%$ [22]. The rest of the load is not uniformly distributed, as aforementioned. The posterior part of the spinal unit receives $40 \%$ of the load, while the anterior part receives only $20 \%$ (Fig. 2) [23]. The posterior annulus fibrosus is thus more strained, which explains the increased probability of developing posterior or posterolateral herniations [24]. This unequal load distribution has an impact both in the degeneration of the posterior vertebral elements and in the morphology of osteoporotic vertebral fractures, as will be explained.

\section{END PLATES}

The end plates are composed of a thin layer of hyaline cartilage half a millimeter in thickness and a layer of cortical bone of the same thickness. They constitute strong docking surfaces for the annulus fibers. The semi-permeable cartilage allows the diffusion of water and solutes to and from the disk while it prevents loss of glycoproteins. 

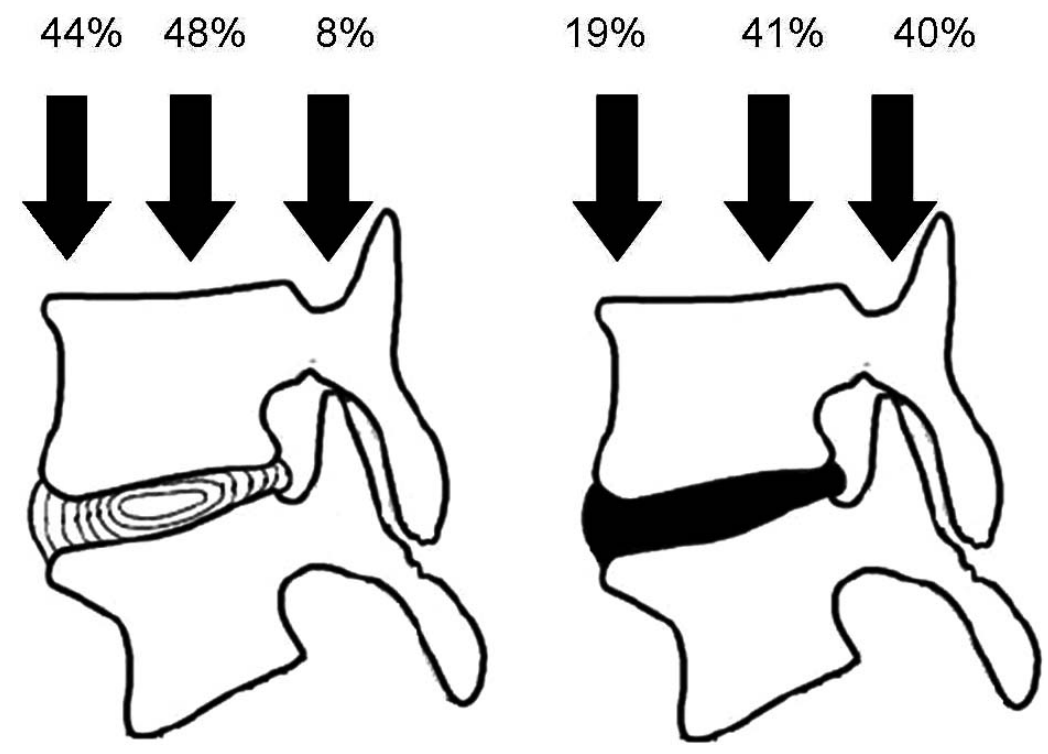

Fig. (2). Load distribution in healthy and degenerate disks. Percentages as described in [22].

The distribution of subchondral bone mineralization within a joint surface is known to reflect the long term distribution of stress over an articular surface. End-plates are thinner in their central parts and thicker in the periphery [2527]. Similarly, strength and stiffness are highest posterolaterally and lowest in the center $[25,28]$. The end plates are constantly subjected to the hydrostatic pressure that develops from the nucleus [29]. It has been discovered that the thickness of the central part of the end-plate is correlated with the proteoglycan and water content of the disk [26]. Thus, in disks where hydrostatic pressure is higher, there is a corresponding increase in end-plate thickness. Additionally, it has been experimentally verified that disk degeneration, with the ensuing decline in hydrostatic pressure, causes a reduction of the end-plates' mechanical strength, especially in the central part [30]. Even when there are no degenerative alterations, the decreasing bone density that is observed with the advancement of age causes a reduction of the end-plates' mechanical strength [30]. The end-plate's mechanical strength therefore depends not only on the bone mineral density of the subchondral bone but also on the remodelling that follows disk degeneration.

The degenerative changes that develop in end-plates replicate those seen in the subchondral bone of large joints [31]. Degeneration initially manifests as an increase in vascularity and subchondral bone edema. This is followed by thinning, fissuring and calcification of cartilage and ultimately subchondral bone sclerosis. These alterations are radiologically defined as Modic type changes, with type I changes representing the hypervascular, proliferative stage of degeneration and type II the subsequent degradative stage [32]. One of the deleterious effects of this process is the disruption of the permeability and hence the transport of nutrients and water to the intervertebral disk [8]. The contribution of this process in the vicious circle of disk degeneration has already been mentioned.

The main biomechanical effect that aging has on the endplates is a reduction in their mechanical strength. Therefore, as age advances, the end-plate becomes more concave, while the disk assumes an oval shape [33]. A weak end-plate however cannot always withstand the loads to which it is subjected and may break. The results of certain experimental studies have demonstrated that the morphology of the endplate's mechanical failure depends mostly on the condition of the disk $[34,35]$. Thus, when the disk is normal, Schmorl nodes crop up through yield points in the majority of cases. Contrarily, when the disk is degenerated, and no nucleus exists to form said nodes, central end plate fractures occur. Bone density was related with how soon these fractures occured (i.e. in how many load cycles) and if it were particularly low the entire vertebral body would break [34].

Schmorl nodes are stable lesions that remain constant over time [36]. In contrast, the occurrence of an end-plate fracture seems to lead to further degeneration of the disk [3739]. An event that is caused or is at least promoted by bone density reduction results in more rapid development of degenerative changes. This is a prime example of how these decay processes can coexist and affect each other.

\section{FACET JOINTS}

The facet joints are true diarthrodial joints, where the joint cavity is surrounded by the joint capsule and synovial membrane, while the surfaces are covered by cartilage. Their role is to assist in load transfer, to stabilize the spinal unit in flexion and extension and to limit axial rotation [40, 41]. These facet joint features are attributed largely to their orientation in the sagittal and transverse planes. This oblique orientation contributes to the resistance to shear forces and to limitation of rotation whilst allowing a bigger range of flexion-extension [1, 40, 42].

During flexion, facet joint capsules, in addition to the posterior ligamentous structures, are stretched, thus limiting movement $[43,44]$. In extension, the joint surfaces come in contact, essentially setting the limit of that motion [43, 44]. During axial rotation, initially the joint capsule on the side opposite to the rotation is stretched and begins to resist [4547], while at the extremes of motion the inferior articular process of the rotating vertebra comes into contact with the superior process of the still vertebra beneath $[41,44]$. The most important facet joint feature is the resistance they exert to shear forces. It has been ascertained experimentally that facet joints resist $77.7 \%$ of anterior and $79 \%$ of posterior 
shear forces [48]. In other words, they inhibit anterior translation during flexion [41] and posterior translation during extension [49]. Additionally, by inhibiting translation, they moreover avert vertebral displacement under the influence of body weight when the trunk is in a horizontal position [41].

Facet joint degeneration follows that of the disk [50-52]. As already mentioned, disk degeneration corresponds to a multiplication of the loads exerted on the facet joints. The result is the development of osteoarthritis, morphologically similar to that of the other diarthrodial joints [53, 54]. Therefore, there is denudation and ulcerative lesions of the articular cartilage, inflammatory hypertrophy of the synovial membrane, formation of osteophytes and sclerosis of the subchondral bone [54, 55]. Degeneration activates a remodelling process which on one hand stabilizes the joint but on the other causes a loss of mobility [43], in the same way as in any other joint.

The facet joints are coronally oriented in the lower lumbar vertebrae, and become more sagittaly so in higher levels [56]. This oblique orientation allows for a broader range of flexion whilst limiting rotation in the lumbar spine [1]. A number of studies have demonstrated the strong association between the increased sagittal orientation and the presence of osteoarthritis, [51,57,58], however it could not be verified whether this orientation predisposes to or is a consequence of osteoarthritis.

The joint capsules are richly innervated by nociceptive and autonomic nerve fibres [59-62]. They are potential sources of pain, the so called "facet joint syndrome". Although this syndrome is controversial, the fact is that facet joint hypertrophy could cause compression of the exiting nerve root, thus resulting in lateral spinal stenosis and root pain [44]. In this particular case, facet joint hypertrophy and osteophyte formation could also lead to other clinical syndromes such as spondylolisthesis and central stenosis, which are described further on.

\section{MUSCLES AND LIGAMENTS}

Muscles and ligaments play a central role in the stability and mobility of the spinal column. Besides their mechanical action in the execution of these actions, they also constitute organs of proprioception. The nerve receptors that are responsible for proprioception and sense of motion are found in the muscles and ligaments of the spine. Activation of these receptors causes reflex responses of the muscles, either those that surround the spine or more distant ones, such as the abdominal muscles. In this way, the spine maintains its balance, performs complex movements but also protects itself from excessive or abnormal motion [21]. It is clear that degeneration of the sensory organs as well as of the end organs of these reflexes disorganizes this complex and sensitive procedure, thus disturbing both kinematics and balance. Therefore the disturbance of normal kinematics and the instability that ensue from the degeneration of these structures are not just biomechanical.

The ligaments of the spine constrain its parts and limit the range of motion in all directions. Due to their elasticity, they passively help return the spine back to the neutral position [63]. The advancement of age leads to an increased percentage of elastin to collagen, increased cross-linking of collagen fibers and finally a reduction in elasticity and strength of ligaments [64]. In addition, the reduction of intervertebral disk height concomitantly reduces the tension on the ligamentum flavum, which as a result of remodelling increases in thickness [6]. The combination of intervertebral disk height reduction together with the thickening and loss of elasticity of the ligamentum flavum result in its folding, thus contributing to the pathogenesis of spinal stenosis.

Spinal muscles are continuously active, and this muscular tone keeps the trunk upright. Without muscular support, the spine has a compression threshold of just $2 \mathrm{~kg}$ before buckling [65]. In both static and dynamic conditions, motion, balance and stability depend on the complex synergistic and competitive actions of the various muscle groups. With the increase in age, muscular fibers are subjected to fatty degeneration, tendons degenerate in a similar manner to ligaments and osteophytes develop on their attachment points. Consequently the generated force is reduced and additionally the motion caused by the muscles is altered, precisely because of the changes in the attachments and of the random way the fibers degenerate. The changes in biomechanics are not yet fully understood, as even the most comprehensive models of spinal muscles are until now incomplete [66].

\section{VERTEBRAL BODY}

The vertebral body receives the largest part of the load that the spine is subjected to. Size increases in the most caudal vertebrae, in agreement with the larger weight they must bear. The entire body is composed of cancellous bone, which becomes more dense and solid around the periphery, to form an outer layer. The vertebral cortex isn't composed of cortical bone, is exceptionally thin [67], and moreover it has been discovered experimentally that it confers only $10 \%$ of the total mechanical strength of vertebrae [68].

The main factor that determines the mechanical strength of the vertebral body is its micro-architecture [69-72]. The bone trabeculae adjacent to the end plate and in the posterior part of the body are larger and their network is more dense and organized. On the contrary, the centre and anterior part of the vertebral body exhibit a smaller regional density with thinner trabeculae and a more irregular structure [73, 74]. This results in an area of reduced strength in the anterior and central part of the vertebral body. When the disk is degenerated, the architecture and the mechanical properties tend to become uniform, evening out any differences $[74$, 75].

The mechanical properties of the vertebral body are also directly related with its mineral density [69-72]. The relationship between bone density and compressive strength is exponential, therefore a small reduction of the former results in a big reduction of the latter [76]. With the increase in age there is an unavoidable loss of bone mass, whose rate rises steeply with the onset of menopause. Moreover, osteoporosis affects vertebral micro-architecture. The densely connected, plate-like trabeculae are transformed into discontinuous rod-like structures $[77,78]$. Together with the reduction in the size and diameter of every trabecula, there is a decline in the number of horizontal trabeculae [79]. These act as cross-links in the overall structure of bone, as they resist bending of the vertical trabeculae (Fig. 3). Hence the 

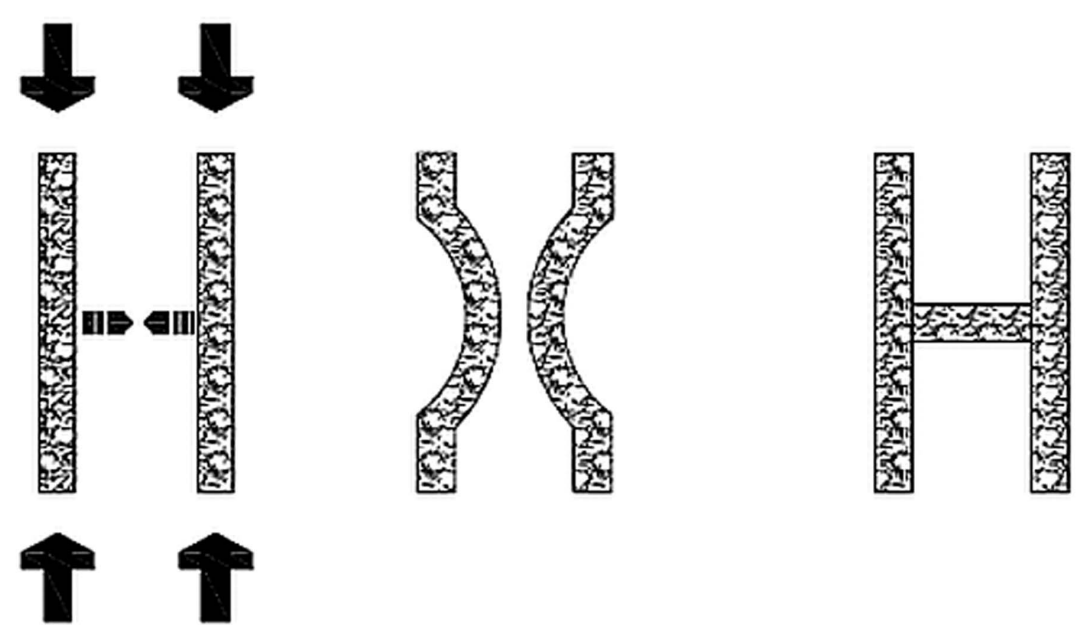

Fig. (3). When two vertical beams are subjected to axial loading, they tend to buckle, either converging, like in the example, or diverging. A cross link prevents this deformation, thus increasing the strength of the vertical beams.

mechanical strength decreases not only because of the smaller quantity of bone but also due to the poorer quality. The end result is that the loads that the vertebral body is subjected to in daily activities exceed its strength. Vertebral osteoporotic fractures can therefore occur even without any violence or exceptionally large loads. Since the anterior part of the vertebral body is less strong, anterior wedge fractures ought to be more frequent, as they indeed are [80].

\section{THE COMBINATION OF OSTEOPOROSIS AND DISK DEGENERATION}

It is relatively uncommon for osteoporosis to be seen in patients with degenerative disk disease [81]. Some researchers have suggested that the presence of one disease excludes the existence of the other [82]. There are those who support that this finding could be a product of DEXA methodology [83]. Specifically, the antero-posterior view that is used for mineral density measurements include bony elements like the facet joints, the transverse and lateral processes and the laminae. The contribution of these elements to the vertebral structural strength is negligible, and additionally they also develop osteophytes, which falsely elevate bone mass. The subject remains controversial, although the fact remains that there are patients with both diseases.

As aforementioned, degeneration of the disk alters the way it transmits loads. The largest part of the load is distributed to the posterior part of the vertebral body, which has a higher regional bone density and greater strength. The anterior part, more fragile from the outset, now receives a smaller part of the loads, with whatever that signifies for bone remodeling [84]. Still, this redistribution of loads means that the greater portion is now exerted on the toughest part of the vertebral body [73]. Nevertheless, during flexion the anterior part receives $50-60 \%$ of loads, regardless of the state of the disk [23, 85]. In agreement with the above, biomechanical experiments have demonstrated that when the spine is axially loaded in the neutral position, compression fractures do not occur in vertebrae adjacent to degenerated disks [86]. When the spine is loaded in flexion, wedge fractures do occur, regardless of the state of the disk. Therefore, biomechanically, when both diseases co-exist, vertebrae are more stable in the neutral position but more susceptible to fracture in flexion. Just as the biomechanical effect of degenerative disk disease is ambiguous as to the overall risk of fracture, clinical studies are ambivalent as to whether disk degeneration increases [87] or reduces [88] fracture frequency.

The forces that are applied on the vertebral body and cause it to fracture are transmitted to the disk. Frank mechanical failure will occur on the vertebral body first and then on the disk, but the disk also get injured [89]. Experimental and biomechanical studies have demonstrated that a fracture has a negative effect on degenerative disk disease, as it results in changes of disk pressure, structural disorders and degeneration [37, 38, 90]. However, clinical observational studies with follow-up of up to 40 years have shown that disks adjacent to fractured vertebrae do not demonstrate degenerative changes [91, 92], except in cases where the end plate had been fractured [39]. Obviously if the disk's structure or blood supply isn't critically injured, the disorder of its composition or nutrient supply will not be enough to lead to degeneration.

\section{CLINICAL SYNDROMES}

Aging of the spine results in a number of painful disorders. The loss of bone mass leads to fractures of the end plate or of the vertebral body. These fractures give rise to pain, loss of height and deformity. Their impact on daily activities and quality of life is also especially detrimental.

Disk degeneration can be a source of significant pain. The infiltrating nerve fibres are activated by the metabolic by-products and inflammatory mediators found in the degenerate disk. Moreover, disk prolapse or herniation can irritate adjacent nerve roots and is in fact the leading cause of radiculopathy.

Facet degeneration is inherently a cause of pain. What's more, facet hypertrophy can compress nerve roots, in addition to the presence of osteophytes that cause irritation. 
This lateral spinal stenosis gives rise to clinical symptoms similar to those of disk herniation [44].

While the disk and facet joints degenerate, they lose the ability to resist shear forces. As a result, they can no longer prevent the forward translation of the vertebra, in other words the development of degenerative spondylolisthesis. Degeneration of the ligaments that support and restrain the spinal column also contributes to this process.

Disk bulging, facet hypertrophy and ligamentum flavum hypertrophy and folding all combine to cause spinal canal stenosis. The condition is aggravated when degenerative spondylolisthesis is also present. Spinal stenosis is a serious disease, particularly when the cervical spine is affected, as it can progress to myelopathy.

The vertebral bodies in the aging spine assume a wedgelike shape, either because of micro-fractures or due to degeneration [93]. This leads to a chain distortion of the configuration of the spine. End-plate or vertebral body fractures will also cause or exacerbate this deformation. In addition, degenerative changes of posterior vertebral elements and disks in conjunction with those of spinal ligaments and muscles result in loss of balance and of normal kinematics. The end result is spinal instability, segmental or generalized. As a consequence of the combination of these alterations, the spine can be destabilized to such a degree that deformities develop such as loss of lordosis, marked kyphosis, degenerative scoliosis or combinations of the above.

The pathophysiologic and biomechanical changes that occur in the spine are the result of the increase in age and the result of other factors. These changes, often but not always, are expressed clinically as pain and disability. Nevertheless, degenerative changes or even osteoporotic fractures can be asymptomatic. The challenge a physician frequently faces in practice is to ascertain whether the patient's symptoms are correlated with the radiologic findings or are non-specific. The diagnosis can be even more complicated when lesions are found in multiple levels. Is therefore becomes apparent that in orthopaedic practice, physical examination remains the most important and useful diagnostic tool.

\section{ACKNOWLEDGEMENT}

None declared.

\section{CONFLICT OF INTEREST}

None declared.

\section{REFERENCES}

[1] White III AA, Panjabi MM. Clinical biomechanics of the spine. 2nd ed. Philadelphia: JB Lippincott Co. 1990.

[2] Frei H, Oxland TR, Nolte LP. Thoracolumbar spine mechanics contrasted under compression and shear loading. J Orthop Res 2002; 20: 1333-8.

[3] Frei H, Oxland TR, Rathonyi GC, Nolte LP. The effect of nucleotomy on lumbar spine mechanics in compression and shear loading. Spine 2001; 26: 2080-9.

[4] Niosi CA, Oxland TR. Degenerative mechanics of the lumbar spine. Spine J 2004; 4: 202S-208S.

[5] Kapandji IA. The physiology of the joints. Volume 3: The trunk and the vertebral column, $6^{\text {th }}$ ed. Churchill Livingstone 2007.

[6] Urban JP, Roberts S. Degeneration of the intervertebral disc. Arthritis Res Ther 2003; 5: 120-30.
[7] Handa T, Ishihara H, Ohshima H, Osada R, Tsuji H, Obata K. Effects of hydrostatic pressure on matrix synthesis and matrix metalloproteinase production in the human lumbar intervertebral disc. Spine 1997; 22: 1085-91.

[8] Boos N, Weissbach S, Rohrbach H, Weiler C, Spratt KF, Nerlich AG. Classification of age-related changes in lumbar intervertebral discs. Spine 2002; 27: 2631-44.

[9] Coppes MH, Marani E, Thomeer RT, Groen GJ. Innervation of "painful" lumbar discs. Spine 1997; 22: 2342-9.

[10] Freemont AJ, Peacock TE, Goupille P, Hoyland JA, O'Brien J, Jayson MI. Nerve ingrowth into diseased intervertebral disc in chronic back pain. Lancet 1997; 350: 178-81.

[11] Ferguson SJ, Steffen T. Biomechanics of the aging spine. Eur Spine J 2003; 12: S97-S103.

[12] Frobin W, Brinckmann P, Kramer M, Hartwig E. Height of lumbar discs measured from radiographs compared with degeneration and height classified from MR images. Eur Radiol 2001; 11: 263-9.

[13] Mimura M, Panjabi MM, Oxland TR, Crisco JJ, Yamamoto I, Vasavada A. Disc degeneration affects the multidirectional flexibility of the lumbar spine. Spine 1994; 19: 1371-80.

[14] Iatridis JC, Setton LA, Foster RJ, Rawlins BA, Weidenbaum M, Mow VC. Degeneration affects the anisotropic and nonlinear behaviors of human anulus fibrosus in compression. J Biomech 1998; 31: 535-44.

[15] Krismer M, Haid C, Behensky H, Kapfinger P, Landauer F, Rachbauer F. Motion in lumbar functional spine units during side bending and axial rotation moments depending on the degree of degeneration. Spine 2000; 25: 2020-7.

[16] Fujiwara A, Lim TH, An HS, et al. The effect of disc degeneration and facet joint osteoarthritis on the segmental flexibility of the lumbar spine. Spine 2000; 25: 3036-44.

[17] Tanaka N, An HS, Lim TH, Fujiwara A, Jeon CH, Haughton VM. The relationship between disc degeneration and flexibility of the lumbar spine. Spine J 2001; 1: 47-56.

[18] Horst M, Brinckmann P. Measurement of the distribution of axial stress on the end-plate of the vertebral body. Spine 1981; 6: 21732.

[19] Iatridis JC, Setton LA, Weidenbaum M, Mow VC. Alterations in the mechanical behavior of the human lumbar nucleus pulposus with degeneration and aging. J Orthop Res 1997; 15: 318-22.

[20] Adams MA, Dolan P, Hutton WC, Porter RW. Diurnal changes in spinal mechanics and their clinical significance. J Bone Joint Surg Br 1990; 72: 266-70.

[21] Adams MA, Dolan P. Spine biomechanics. J Biomech 2005; 38: 1972-83.

[22] Pollintine P, Przybyla AS, Dolan P, Adams MA. Neural arch loadbearing in old and degenerated spines. J Biomech 2004; 37: 197204.

[23] Pollintine P, Dolan P, Tobias JH, Adams MA. Intervertebral disc degeneration can lead to "stress-shielding" of the anterior vertebral body: a cause of osteoporotic vertebral fracture? Spine 2004; 29: 774-82.

[24] Adams MA, McNally DS, Dolan P. 'Stress' distributions inside intervertebral discs. The effects of age and degeneration. J Bone Joint Surg Br 1996; 78: 965-72.

[25] Grant JP, Oxland TR, Dvorak MF. Mapping the structural properties of the lumbosacral vertebral endplates. Spine 2001; 26: 889-96.

[26] Edwards WT, Zheng Y, Ferrara LA, Yuan HA. Structural features and thickness of the vertebral cortex in the thoracolumbar spine. Spine 2001; 26: 218-25.

[27] Roberts S, McCall IW, Menage J, Haddaway MJ, Eisenstein SM. Does the thickness of the vertebral subchondral bone reflect the composition of the intervertebral disc? Eur Spine J 1997; 6: 385-9.

[28] Lowe TG, Hashim S, Wilson LA, et al. A biomechanical study of regional endplate strength and cage morphology as it relates to structural interbody support. Spine 2004; 29: 2389-94.

[29] Broberg KB. On the mechanical behaviour of intervertebral discs. Spine 1983; 8: 151-65.

[30] Grant JP, Oxland TR, Dvorak MF, Fisher CG. The effects of bone density and disc degeneration on the structural property distributions in the lower lumbar vertebral endplates. J Orthop Res 2002; 20: 1115-20

[31] Moore RJ. The vertebral endplate: disc degeneration, disc regeneration. Eur Spine J 2006; 15: S333-7. 
[32] Rahme R, Moussa R. The modic vertebral endplate and marrow changes: pathologic significance and relation to low back pain and segmental instability of the lumbar spine. AJNR Am J Neuroradiol 2008; 29: 838-42.

[33] Twomey LT, Taylor JR. Age changes in lumbar vertebrae and intervertebral discs. Clin Orthop Relat Res 1987; (224): 97-104.

[34] Hansson TH, Keller TS, Spengler DM. Mechanical behavior of the human lumbar spine. II. Fatigue strength during dynamic compressive loading. J Orthop Res 1987; 5(4): 479-87.

[35] Hansson T, Keller T, Jonson R. Fatigue fracture morphology in human lumbar motion segments. J Spinal Disord 1988; 1: 33-8.

[36] Girard CJ, Schweitzer ME, Morrison WB, Parellada JA, Carrino JA. Thoracic spine disc-related abnormalities: longitudinal MR imaging assessment. Skeletal Radiol 2004; 33: 216-22.

[37] Holm S, Holm AK, Ekström L, Karladani A, Hansson T. Experimental disc degeneration due to endplate injury. J Spinal Disord Tech 2004; 17: 64-71

[38] Haschtmann D, Stoyanov JV, Gédet P, Ferguson SJ. Vertebral endplate trauma induces disc cell apoptosis and promotes organ degeneration in vitro. Eur Spine J 2008; 17: 289-99.

[39] Kerttula LI, Serlo WS, Tervonen OA, Pääkkö EL, Vanharanta HV. Post-traumatic findings of the spine after earlier vertebral fracture in young patients: clinical and MRI study. Spine 2000; 25: 1104-8.

[40] Adams MA, Hutton WC. The mechanical function of the lumbar apophyseal joints. Spine 1983; 8: 327-30.

[41] Adams MA. Biomechanics of back pain. Acupunct Med 2004; 22: 178-88.

[42] Adams MA, Hutton WC. The effect of posture on the lumbar spine. J Bone Joint Surg Br 1985; 67: 625-9.

[43] Serhan HA, Varnavas G, Dooris AP, Patwadhan A, Tzermiadianos M. Biomechanics of the posterior lumbar articulating elements. Neurosurg Focus 2007; 22: E1.

[44] Kalichman L, Hunter DJ. Lumbar facet joint osteoarthritis: a review. Semin Arthritis Rheum 2007; 37: 69-80.

[45] Tanno I, Murakami G, Oguma H, et al. Morphometry of the lumbar zygapophyseal facet capsule and cartilage with special reference to degenerative osteoarthritic changes: an anatomical study using fresh cadavers of elderly Japanese and Korean subjects. J Orthop Sci 2004; 9: 468-77.

[46] Boszczyk BM, Boszczyk AA, Korge A, et al. Immunohistochemical analysis of the extracellular matrix in the posterior capsule of the zygapophysial joints in patients with degenerative L4-5 motion segment instability. J Neurosurg 2003; 99: 27-33.

[47] Tischer T, Aktas T, Milz S, Putz RV. Detailed pathological changes of human lumbar facet joints L1-L5 in elderly individuals. Eur Spine J 2006; 15: 308-15.

[48] Lu WW, Luk KD, Holmes AD, Cheung KM, Leong JC. Pure shear properties of lumbar spinal joints and the effect of tissue sectioning on load sharing. Spine 2005; 30: E204-9.

[49] Cyron BM, Hutton WC. The tensile strength of the capsular ligaments of the apophyseal joints. J Anat 1981; 132: 145-50.

[50] Butler D, Trafimow JH, Andersson GB, McNeill TW, Huckman MS. Discs degenerate before facets. Spine 1990; 15: 111-3.

[51] Fujiwara A, Tamai K, An HS, et al. Orientation and osteoarthritis of the lumbar facet joint. Clin Orthop Relat Res 2001; (385): 88-94.

[52] Fujiwara A, Tamai K, Yamato M, et al. The relationship between facet joint osteoarthritis and disc degeneration of the lumbar spine: an MRI study. Eur Spine J. 1999; 8: 396-401.

[53] Grenier N, Kressel HY, Schiebler ML, Grossman RI, Dalinka MK. Normal and degenerative posterior spinal structures: MR imaging. Radiology 1987; 165: 517-25.

[54] Benoist M. Natural history of the aging spine. Eur Spine J 2003; 12: S86-9.

[55] Eisenstein SM, Parry CR. The lumbar facet arthrosis syndrome. Clinical presentation and articular surface changes. J Bone Joint Surg Br 1987; 69: 3-7.

[56] Panjabi MM, Oxland T, Takata K, Goel V, Duranceau J, Krag M. Articular facets of the human spine. Quantitative three-dimensional anatomy. Spine 1993; 18: 1298-310.

[57] Grogan J, Nowicki BH, Schmidt TA, Haughton VM. Lumbar facet joint tropism does not accelerate degeneration of the facet joints. AJNR Am J Neuroradiol 1997; 18: 1325-9.

[58] Berlemann U, Jeszenszky DJ, Bühler DW, Harms J. Facet joint remodeling in degenerative spondylolisthesis: an investigation of joint orientation and tropism. Eur Spine J 1998; 7: 376-80.
[59] Giles LG, Harvey AR. Immunohistochemical demonstration of nociceptors in the capsule and synovial folds of human zygapophyseal joints. Br J Rheumatol 1987; 26: 362-4.

[60] Giles LG, Taylor JR. Human zygapophyseal joint capsule and synovial fold innervation. Br J Rheumatol 1987; 26: 93-8.

[61] Giles LG, Taylor JR. Innervation of lumbar zygapophyseal joint synovial folds. Acta Orthop Scand 1987; 58: 43-6.

[62] Ashton IK, Ashton BA, Gibson SJ, Polak JM, Jaffray DC, Eisenstein SM. Morphological basis for back pain: the demonstration of nerve fibers and neuropeptides in the lumbar facet joint capsule but not in ligamentum flavum. J Orthop Res 1992; 10: $72-8$.

[63] Schendel MJ, Wood KB, Buttermann GR, Lewis JL, Ogilvie JW. Experimental measurement of ligament force, facet force, and segment motion in the human lumbar spine. J Biomech 1993; 26: 427-38.

[64] Panjabi MM, Goel VK, Takata K. Physiologic strains in the lumbar spinal ligaments. An in vitro biomechanical study. Spine 1982; 7 : 192-203.

[65] Kiefer A, Shirazi-Adl A, Parnianpour M. Synergy of the human spine in neutral postures. Eur Spine J 1998; 7: 471-9.

[66] Hansen L, de Zee M, Rasmussen J, Andersen TB, Wong C, Simonsen EB. Anatomy and biomechanics of the back muscles in the lumbar spine with reference to biomechanical modeling. Spine 2006; 31: 1888-99.

[67] Silva MJ, Wang C, Keaveny TM, Hayes WC. Direct and computed tomography thickness measurements of the human, lumbar vertebral shell and endplate. Bone 1994; 15: 409-14.

[68] Silva MJ, Keaveny TM, Hayes WC. Load sharing between the shell and centrum in the lumbar vertebral body. Spine 1997; 22: 140-50.

[69] Singer K, Edmondston S, Day R, Breidahl P, Price R. Prediction of thoracic and lumbar vertebral body compressive strength: correlations with bone mineral density and vertebral region. Bone 1995; 17: 167-74.

[70] Buckley JM, Loo K, Motherway J. Comparison of quantitative computed tomography-based measures in predicting vertebral compressive strength. Bone 2007; 40: 767-74.

[71] Lochmüller EM, Pöschl K, Würstlin L, et al. Does thoracic or lumbar spine bone architecture predict vertebral failure strength more accurately than density? Osteoporos Int 2008; 19: 537-45.

[72] Prakash, Prabhu LV, Saralaya VV, et al. Vertebral body integrity: a review of various anatomical factors involved in the lumbar region. Osteoporos Int 2007; 18: 891-903.

[73] Hulme PA, Boyd SK, Ferguson SJ. Regional variation in vertebral bone morphology and its contribution to vertebral fracture strength. Bone 2007; 41: 946-57.

[74] Keller TS, Moeljanto E, Main JA, Spengler DM. Distribution and orientation of bone in the human lumbar vertebral centrum. J Spinal Disord 1992; 5: 60-74.

[75] Keller TS, Ziv I, Moeljanto E, Spengler DM. Interdependence of lumbar disc and subdiscal bone properties: a report of the normal and degenerated spine. J Spinal Disord 1993; 6: 106-13.

[76] Keller TS. Predicting the compressive mechanical behavior of bone. J Biomech 1994; 27: 1159-68.

[77] Amling M, Pösl M, Ritzel H, et al. Architecture and distribution of cancellous bone yield vertebral fracture clues. A histomorphometric analysis of the complete spinal column from 40 autopsy specimens. Arch Orthop Trauma Surg 1996; 115: 262-9.

[78] Briggs AM, Greig AM, Wark JD, Fazzalari NL, Bennell KL. A review of anatomical and mechanical factors affecting vertebral body integrity. Int J Med Sci 2004; 1: 170-180.

[79] McDonnell P, McHugh PE, O'Mahoney D. Vertebral osteoporosis and trabecular bone quality. Ann Biomed Eng 2007; 35: 170-89.

[80] Ismail AA, Cooper C, Felsenberg D, et al. Number and type of vertebral deformities: epidemiological characteristics and relation to back pain and height loss. European Vertebral Osteoporosis Study Group. Osteoporos Int 1999; 9: 206-13.

[81] Miyakoshi N, Itoi E, Murai H, Wakabayashi I, Ito H, Minato T. Inverse relation between osteoporosis and spondylosis in postmenopausal women as evaluated by bone mineral density and semiquantitative scoring of spinal degeneration. Spine $2003 ; 28$ : 492-5.

[82] Dequeker J, Aerssens J, Luyten FP. Osteoarthritis and osteoporosis: clinical and research evidence of inverse relationship. Aging Clin Exp Res 2003; 15: 426-39. 
[83] Sapkas GS, Papagelopoulos PJ, Stathakopoulos DP, Papadakis SA, Kiratzoulis JM, Stilianessi E. Evaluation of lumbar spine bone mineral density in the anteroposterior and lateral projections by dual-energy X-ray absorptiometry. Orthopedics 2001; 24: 959-63.

[84] Simpson EK, Parkinson IH, Manthey B, Fazzalari NL. Intervertebral disc disorganization is related to trabecular bone architecture in the lumbar spine. J Bone Miner Res 2001; 16: 6817.

[85] Adams MA, Pollintine P, Tobias JH, Wakley GK, Dolan P. Intervertebral disc degeneration can predispose to anterior vertebral fractures in the thoracolumbar spine. J Bone Miner Res 2006; 21: 1409-16.

[86] Shirado O, Kaneda K, Tadano S, Ishikawa H, McAfee PC, Warden KE. Influence of disc degeneration on mechanism of thoracolumbar burst fractures. Spine 1992; 17: 286-92.

[87] Sornay-Rendu E, Allard C, Munoz F, Duboeuf F, Delmas PD. Disc space narrowing as a new risk factor for vertebral fracture: the OFELY study. Arthritis Rheum 2006; 54: 1262-9.

[88] Roux C, Fechtenbaum J, Briot K, Cropet C, Liu-Léage S, Marcelli C. Inverse relationship between vertebral fractures and spine osteoarthritis in postmenopausal women with osteoporosis. Ann Rheum Dis 2008; 67: 224-8.

[89] Brinckmann P. Injury of the annulus fibrosus and disc protrusions. An in vitro investigation on human lumbar discs. Spine 1986; 11 : 149-53.

[90] Adams MA, Freeman BJ, Morrison HP, Nelson IW, Dolan P. Mechanical initiation of intervertebral disc degeneration. Spine 2000; 25: 1625-36.

[91] Möller A, Maly P, Besjakov J, Hasserius R, Ohlin A, Karlsson MK. A vertebral fracture in childhood is not a risk factor for disc degeneration but for Schmorl's nodes: a mean 40-year observational study. Spine 2007; 32: 2487-92.

[92] Moller A, Hasserius R, Redlund-Johnell I, Ohlin A, Karlsson MK. Nonoperatively treated burst fractures of the thoracic and lumbar spine in adults: a 23-to 41-year follow-up. Spine J 2007; 7: 701-7.

[93] Abdel-Hamid Osman A, Bassiouni H, Koutri R, Nijs J, Geusens P, Dequeker J. Aging of the thoracic spine: distinction between wedging in osteoarthritis and fracture in osteoporosis--a crosssectional and longitudinal study. Bone 1994; 15: 437-42.

(C) Papadakis et al.; Licensee Bentham Open.

This is an open access article licensed under the terms of the Creative Commons Attribution Non-Commercial License (http://creativecommons.org/licenses/by-nc/3.0/) which permits unrestricted, non-commercial use, distribution and reproduction in any medium, provided the work is properly cited. 